\title{
Wind Technology and Associated Carbon Footprint
}

\author{
Lisa Ann Lamont ${ }^{1, *}$ and Lana El Chaar ${ }^{2}$ \\ ${ }^{1}$ Transmission and Distribution Division, Mott MacDonald, Glasgow, UK \\ ${ }^{2}$ Power Generation Services, GE, Dubai, UAE
}

\begin{abstract}
Renewable energies such as solar and wind are now widely accepted as possible future energy sources to enhance the energy demands and support the intense desire to reduce the worldwide carbon footprint. Over the last few years, renewable energy sources have won the legislative support of governments in several countries. The main reason for this boom is the need to use alternative energy sources, to fossil fuel, which are free of $\mathrm{CO}_{2}$ emissions and contamination. Unfortunately there are no renewable energy sources that can currently account for zero carbon footprints due to the fact that it is divided into two elements direct and indirect. The direct or primary carbon footprint is related to the $\mathrm{CO}_{2}$ emitted when burning fossil fuels in such areas as transportation and domestic energy consumption. As well as the direct carbon footprint which is universally accepted, there is also an indirect or secondary element which is associated with the life cycle of the products. The problem is how can this indirect carbon footprint be considered or included when discussing the total impact of renewable energy sources.

Life Cycle Assessment is a method used to identify the main types of impact on the environment a wind turbine can cause throughout its 20 year life of operation. Emissions produced while wind turbines are in operation in addition to factors from the start of the manufacturing process to the last stage where dismantling is required at end-of-life. Life cycle assessment showed that wind turbines are not carbon neutral as they have an indirect carbon footprint. However, when compared with traditional energy sources the carbon footprint for non-traditional energy forms is still significantly limited.
\end{abstract}

Keywords: Wind technology, carbon footprint, indirect carbon footprint, direct carbon footprint.

\section{INTRODUCTION}

A chain effect has begun worldwide with the population rise leading to a vast increase of power generation which in turn is a major cause of global warming because of the greenhouse gas emissions produced during the production of electricity. Hence there is a need to develop new technologies which operate predominantly with minimum pollution. Renewable energy sources, such as solar and wind have been widely accepted as possible sustainable energy sources to complement and support the traditional power sources as the demand increases as well as supporting the desire to reduce the worldwide carbon footprint. Many people consider renewable technologies to be excellent for the environment as during power production they do not produce any carbon dioxide $\left(\mathrm{CO}_{2}\right)$, however, there are no renewable energy sources that can currently account for zero carbon footprint. It is known that wind turbines are green technologies because of their low environmental impact during their usage but, very little attention has been given to the life-cycle of these devices and the emissions that could be produced due to this. Normally when the "greenness" of a wind technology is being discussed, the manufacturing processes as well as

*Address correspondence to this author at the Transmission and Distribution Division, Mott MacDonald, Glasgow, UK; Tel: +44(0)141222 9162;

Fax: +44(0)141 221 2048; E-mail: Lisa.lamont@mottmac.com product waste disposal at the end of its lifetime are never considered when evaluating the emissions these technologies release. It is true that their environmental impact is a lot smaller than traditional sources but it cannot be completely neglected (Figure 1) [1].

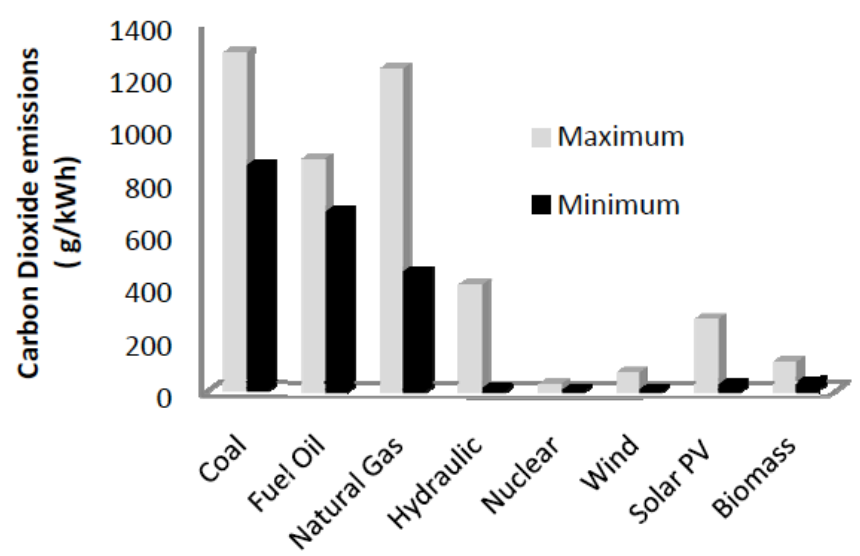

Figure 1: Total Carbon Dioxide Emissions [2].

As carbon dioxide emissions is split into two sections - direct, in this case the wind turbine produces no $\mathrm{CO}_{2}$, and indirect $\mathrm{CO}_{2}$ where the wind turbine produces a limited amount of carbon dioxide. It must also be remembered that wind energy is intermittent; hence fossil fuel capacity operating as reserve and backup is then needed to supplement the electricity generation and stabilize supplies to the consumer. Using this to balance the fluctuating demand and unpredictable wind output, has shown $\mathrm{CO}_{2}$ emissions 


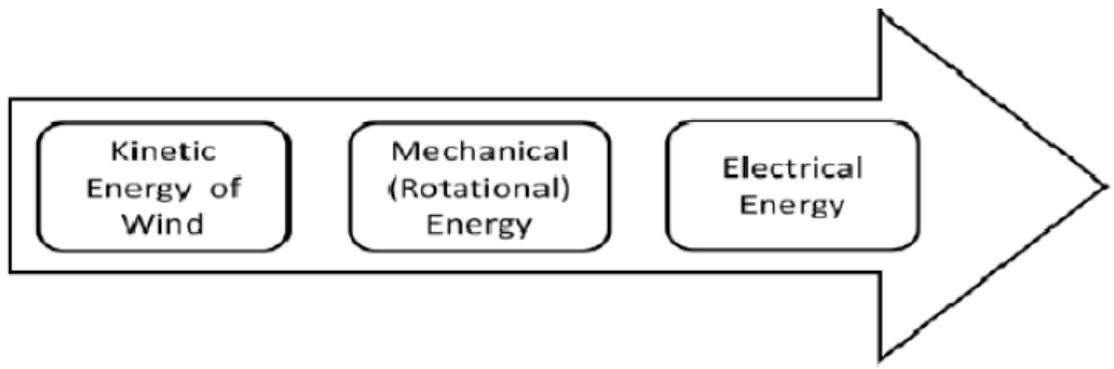

Figure 2: Flow of Energy Conversion of a Wind Turbine.

which are higher than normal - even more than when operating a fossil fuel plant in normal operating mode [3].

\section{HARNESSING WIND ENERGY}

Wind energy is defined as the process by which wind is applied to generate mechanical power or electricity as depicted in Figure $\mathbf{2}$.

Wind turbines (WT) are the devices used to harness wind and convert the kinetic energy into mechanical which in turn is converted into electrical energy [4, 5]. The three major components for these energy conversion devices are rotor, gear box and generator. The rotor converts the varying wind energy into mechanical energy while the generator with the aid of electronic devices absorb the mechanical power and changes it into electrical energy, which is then fed into a supply grid. Finally, the gear box adjusts the speed between the rotor and its shaft and the generator speed. Figure 3 represents a block diagram of a total power production system from the wind technology which captures the energy to the grid to supply power for the consumers.

Wind energy technologies (WET) [6, 7] over the years have developed in two main strands: horizontal axis wind turbines (HAWT) [8-10] and vertical axis wind turbine (VAWT) [11-14] (Figure 4). Research shows that HAWT are more commonly used today especially in utility scale projects due to their potential for higher power generation. Each HAWT includes a rotor (blades), a nacelle (enclosure for generator and gearbox), a tower and electronic control equipment which when combined together converts the kinetic energy into electrical energy. Meanwhile, VAWTs were evolving but at a slower rate due to lack of interest and financial support. WECS, no matter whether horizontal or vertical, both depend on aerodynamic lift [15] using blades to interact with the incoming wind. In order to produce clean power for residential, small businesses, farms and community applications, small and mid-sized

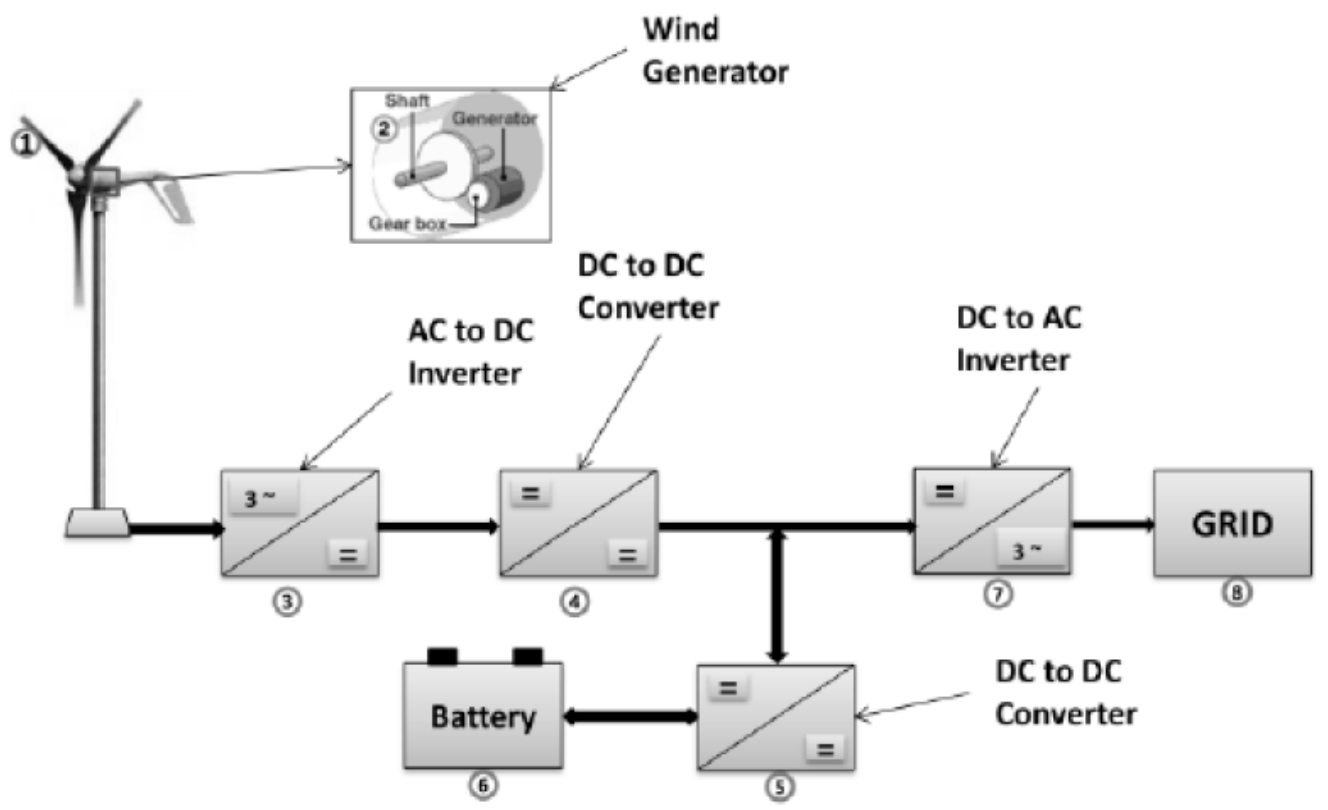

Figure 3: Wind Energy Electricity Generation Block Diagram. 
wind turbines have been developed. Small wind turbines, with power ratings below $100 \mathrm{~kW}$ are mostly dedicated to power up houses, offices and farm equipment. Turbines with power capacity between 100 $\mathrm{kW}$ and $1 \mathrm{MW}$ are called mid-size turbines and are normally used to supply power for certain applications in industry and community sectors. There is an increasing trend towards larger scale wind turbines with the aim of providing higher efficiencies and larger energy output per turbine. However with such growth comes an inherent increase in the quantity of materials and energy needed for manufacturing and installation.

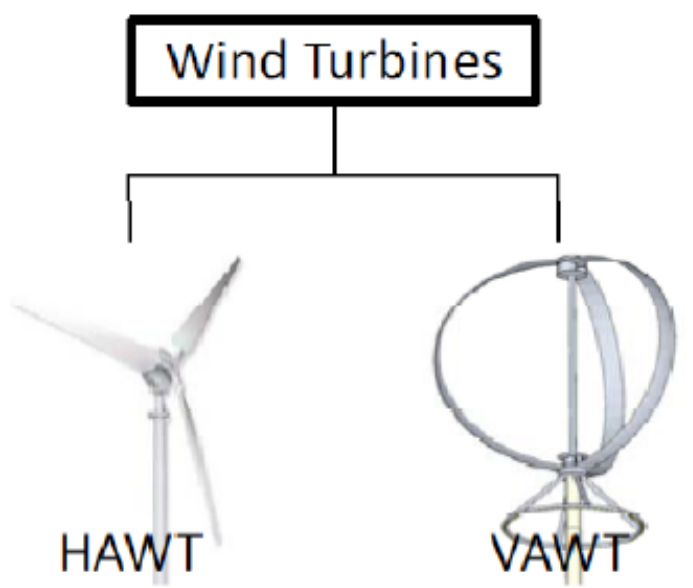

Figure 4: VAWT and HAWT.

The amount of electricity generated by the turbines depends on the turbine's size and wind speed through the rotor as shown in (1)

$$
P_{W T}=\frac{1}{2} C_{p} \pi R^{2} \rho v^{3}
$$

where $C_{p}$ is the wind power coefficient, $R$ is the rotor blade radius $(\mathrm{m}), \rho$ is the wind density $\left(\mathrm{kg} / \mathrm{m}^{3}\right)$ and $v$ is the wind speed $(\mathrm{m} / \mathrm{s})$. As noted, the power available from the turbine is proportional to the wind speed cubed. One method of measuring the productivity of a wind turbine or any power facility is by analyzing the capacity factor which is defined as the amount of power generated by the plant at full capacity [15]

$$
\begin{aligned}
\text { Capacity Factor }= & \frac{\text { actual amount of power produced over time }}{\text { power that would have been produced if turbine }} \\
& \text { is operated at maximum output } 100 \% \text { of the time }
\end{aligned}
$$

By implementing this calculation, it is stated in reference [15] that the capacity factor of wind is $25 \%$ to $40 \%$, while conventional plants have a capacity factor of $40 \%$ to $80 \%$. This factor could be increased by reducing the generator size and enlarging the blades; however a negative factor with this principle is that the amount of electricity generated is reduced. It must be remembered that the major advantage of deploying this technology is that the electricity it produces is clean and non-polluting [16] since it does not use any combustion method for electricity generation; hence has no negative impact on the environment and in particular global warming. Nevertheless, some limited environmental impacts are associated with wind technologies and in order to fully understand them, a "cradle-to-grave assessment" [16] is required to comprehend their effect on the carbon footprint.

\section{CARBON FOOTPRINT PROTOCOLS}

With all energy sources renewable or traditional forms, the main concern is related to their footprint which is the total amount of $\mathrm{CO}_{2}$ and other greenhouse gases (GHG) emitted during the full life cycle of any product. Hence, it measures the total greenhouse gas emissions caused directly and indirectly and considers all six of the Kyoto Protocol greenhouse gases: Carbon dioxide $\left(\mathrm{CO}_{2}\right)$, Methane $\left(\mathrm{CH}_{4}\right)$, Nitrous oxide $\left(\mathrm{N}_{2} \mathrm{O}\right)$, Hydrofluorocarbons (HFCs), Perfluorocarbons (PFCs) and Sulphur hexafluoride $\left(\mathrm{SF}_{6}\right)$ [17] (Figure 5).

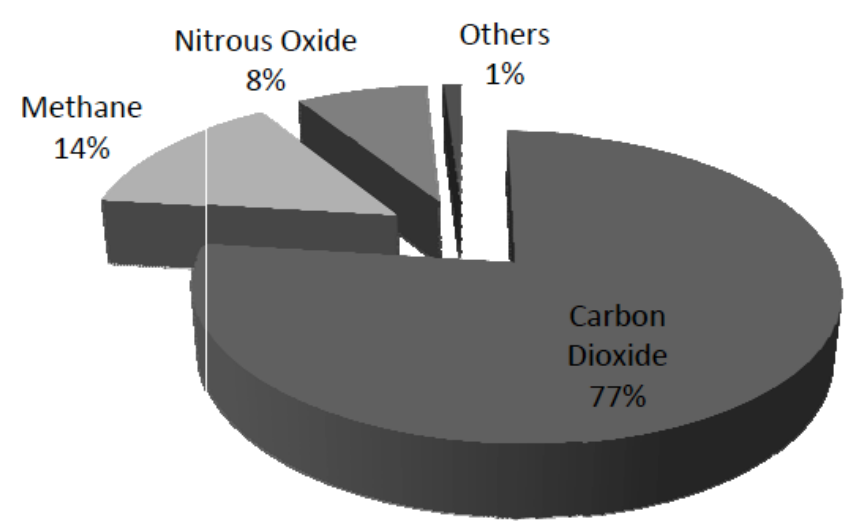

Figure 5: Distribution of Greenhouse Gases [18].

Although carbon footprint is a frequently used phrase, few clear definitions can be found in literature, it is described as "a measure of the impact human activities have on the environment in terms of the amount of greenhouse gases produced, measured in tonnes of carbon dioxide" [19]. Others defined carbon footprint, as "the total amount of $\mathrm{CO}_{2}$ emitted and it is normally quantified in grams of $\mathrm{CO}_{2}$ equivalent per kilowatt hour (kWh) of generation" [20]. It can also be measured in tonnes of carbon dioxide equivalent $\left(\mathrm{tCO}_{2} \mathrm{e}\right)$. The Carbon Trust defined it as"... a methodology to estimate the total emission of greenhouse gases (GHG) in carbon equivalents from a product across its life cycle from the production of raw 
material used in its manufacture, to disposal of the finished product (excluding in-use emissions)" [21]. Also, it is defined as "... a measure of the exclusive amount of carbon dioxide emissions that is directly and indirectly caused by an activity or is accumulated over the life stages of a product" [21].

By the various definitions, it can be summarized as for a certain amount of gaseous emissions that are impacting climate change due to an individual's production or consumption of various activities. This can be further divided into the primary footprint (scope 1 and 2) which is a measure of the direct emissions of $\mathrm{CO}_{2}$ from the burning of fossil fuels (energy consumption and transportation) while the secondary footprint (scope 3 ) is the indirect $\mathrm{CO}_{2}$ emissions from the whole lifecycle of products (manufacture, waste disposal) as represented in Figure 6.

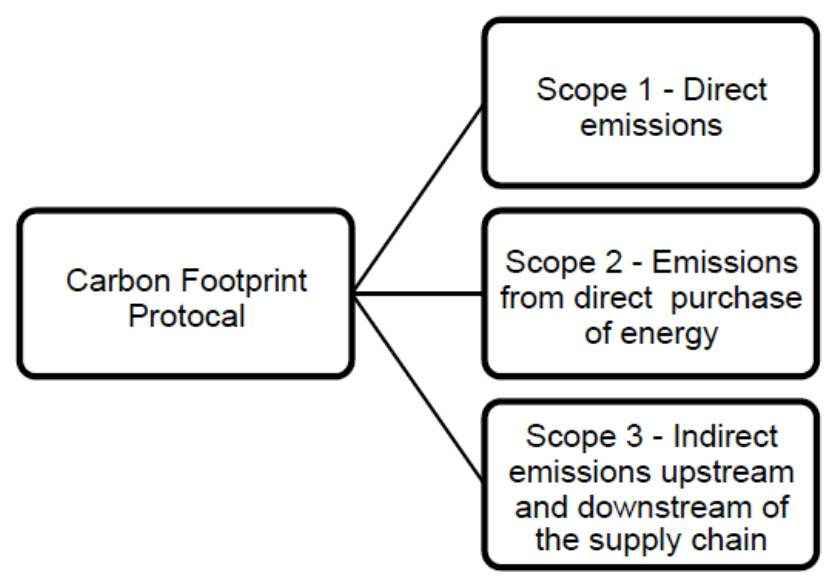

Figure 6: Carbon Footprint Protocols [22-24].

Predominantly people are more concerned with the direct emissions, however when studying and analyzing the carbon footprints and assessing them to conclude if a certain product is carbon neutral, it is then necessary to investigate the full life cycle from production to disposal. As renewable energy technologies are introduced to mitigate carbon emissions, it is necessary to appraise their carbon footprint to build a clearer case for selecting a source when more than one technology is suitable for certain applications. In this paper, to ensure complete assessment of the wind turbine technology footprint, the production of each component must be carefully studied while evaluating its lifetime, material used, transport and energy requirements for processing, disposal and land usage. The grid system which connects the wind technology to the consumer supply also has a carbon footprint but this will not be discussed in this paper as it is considered the grid will be the same whether the supply is a renewable or traditional source.

\section{DIRECT CARBON EMISSIONS}

This section further discusses the direct carbon emissions which were previously highlighted in Figure 6 and divided into scope 1 (direct emissions) and scope 2 (emissions from direct purchase of energy). Specific sectors such as the electrical generation industry, natural gas and petroleum combustion businesses, cement and steel manufacturers and transportation systems are commonly known as high direct carbon emitters. The combination of all these along with other outputs account for approximately $93 \%$ of the total emissions in some of the developed countries with this further being split between into direct $2 / 3$ and indirect $1 / 3$ [24]. To reduce the amount of direct emissions, there are two possible options. The first considers the traditional energy sources and ensures they operate in an efficient manner. This is not only the cheapest approach for reducing the emissions but it will ensure a security of continuous supply. Secondly, non-fossil fuel based technologies such as wind turbines can also be considered a solution for $\mathrm{CO}_{2}$ mitigation since they are "low carbon" because of their zero direct emission; nevertheless, indirect emissions are still a significant factor which needs to be considered.

\section{INDIRECT CARBON EMISSIONS}

The manufacturing of wind turbines, although not complicated, contains vital elements such as material processing and construction which require considerable energy consumption hence large greenhouse gas emissions [25]. Life cycle assessment (LCA) [26] is the method utilized to study the cumulative environmental impacts of wind energy technologies. It includes relevant upstream and downstream processes within the energy sequence, this LCA calculation takes into account several steps in the implementation, maintenance and decommissioning phases. Different types of LCA analysis have been developed in recent years due to the growth of wind energy applications. Such studies have been performed to assess the impact of wind energy systems on the performance as well as on the environment. The LCA methodologies vary as they look at various turbine types however few of them considered modern multi-megawatt turbines rather most of the methods looked at very small turbine sizes [27]. Some studies investigated the net energy return 
and greenhouse emissions [28, 29] while others estimated other environmental impacts [30, 31]. The major critical aspects of the reviewed LCAs are based on the following factors:-

- $\quad$ Energy use and electrical energy conversions types of energy carriers used and their conversion to primary energy.

- $\quad$ Electrical energy production and energy payback ratios - electrical energy produced is compared to the energy used during their life cycle to express the amount of net energy gained.

- $\quad$ Material resource use - some material that make up a certain part of turbine based on a cut-off criteria related to the percentage of a material from the cumulative mass.

- $\quad$ Recycling - the international standards of LCA states that the approach of inflows and outflows of recycled materials should be consistent [32]. This approach is supported by metal industries such as aluminum and copper. However, there are several reasons why such approach is dubious as one of these factors is related to the moment in time when emissions occur as the effect of ions released today but this still has an effect after 20 years and until the material is recycled. This makes the evaluation of $\mathrm{CO}_{2}$ emissions not accurate.

- $\quad$ Capacity factors and projected production - this is a most important and critical factor in the life cycle analysis as it is related to the estimated energy production which correlates with the capacity factor which is normally assumed to be high. This in turn impacts the total production of electrical energy which in turn lowers the emissions.

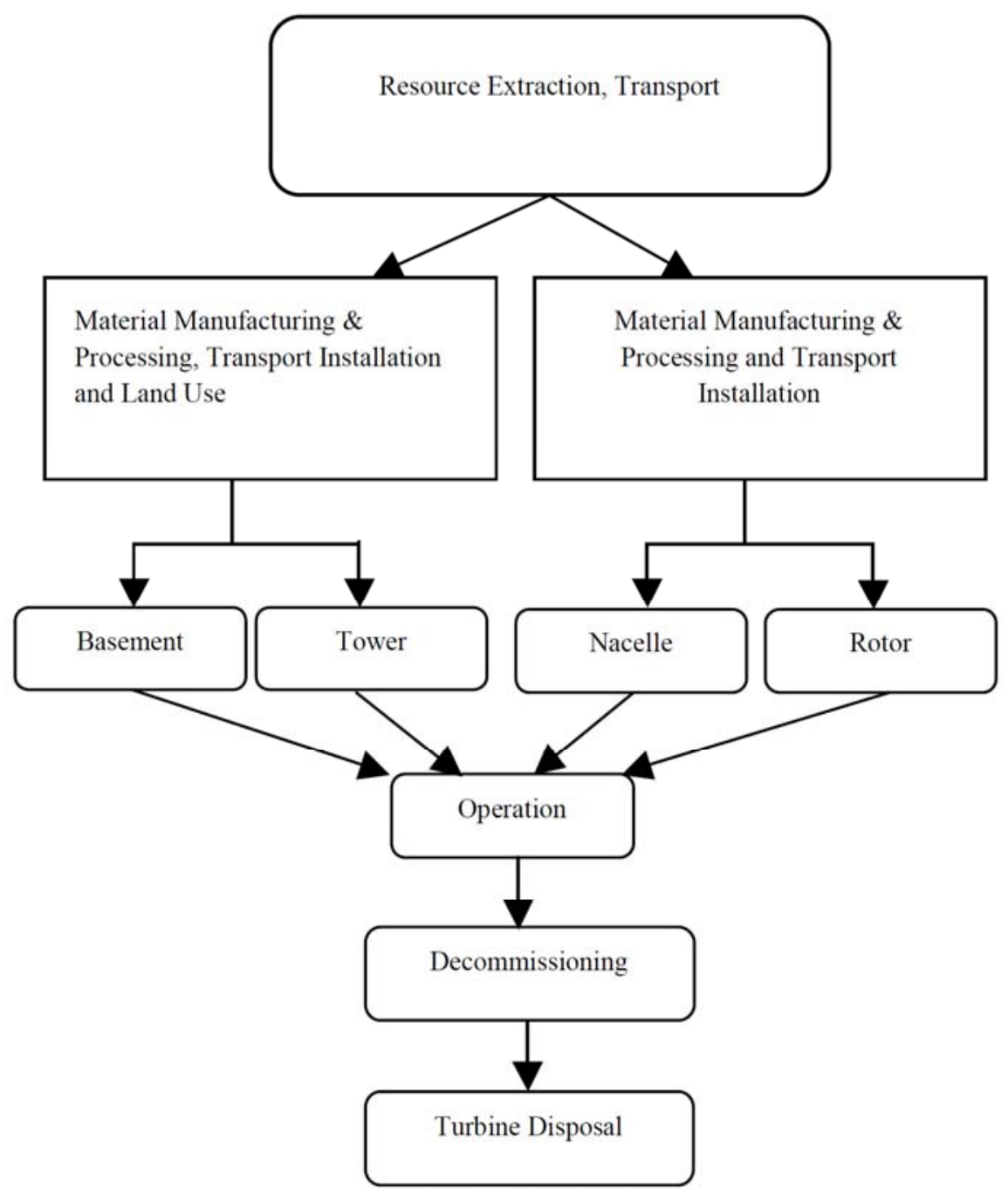

Figure 7: LCA Inventory [31]. 
In order to make LCAs more practical, other factors are to be considered such as the life cycle inventory (Figure 7) where actual inventory of inputs and outputs of mass and energy requiring the collection of relevant data of materials and processes is included.

With relation to the wind turbine, there are certain areas where "hidden" emissions are prevalent (Figure 8). This can be summarized under the headings of construction, transport, operation and decommissioning.

- $\quad$ Construction - extraction and processing of raw material required for manufacturing of the tower, nacelle, blades, foundations and grid connections.

- Transport - transportation of raw material for construction, of turbine to the generation site, during operation, for maintenance and when dismantling is all included.

- Operation - all work that is related to maintenance such as oil lubrication and component replacement.

- Decommissioning - recycling of material and disposal of waste.

The first stage of the WT which sees carbon emissions is the manufacturing process. It is known that this part of the development is a great contributor to the emission of carbon due to the energy consumption required. However, this is impacted further depending on whether raw or recycled material is used in the turbines' construction. A study was undertaken on the production of two different sizes of WT using virgin (raw) and recycled material and Figure 9 summarizing the results.

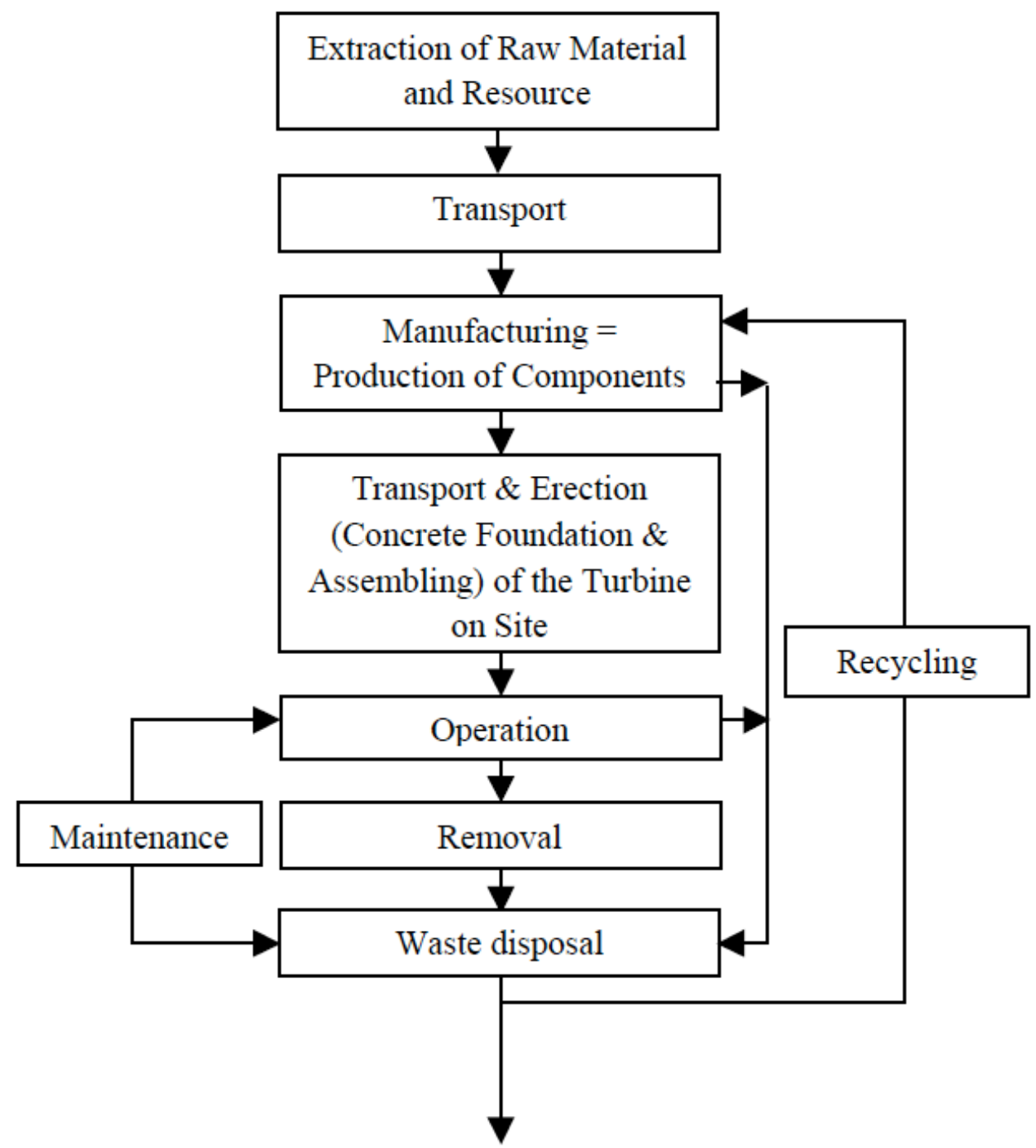

Figure 8: Flowchart Representation of Wind Turbine Life [33]. 


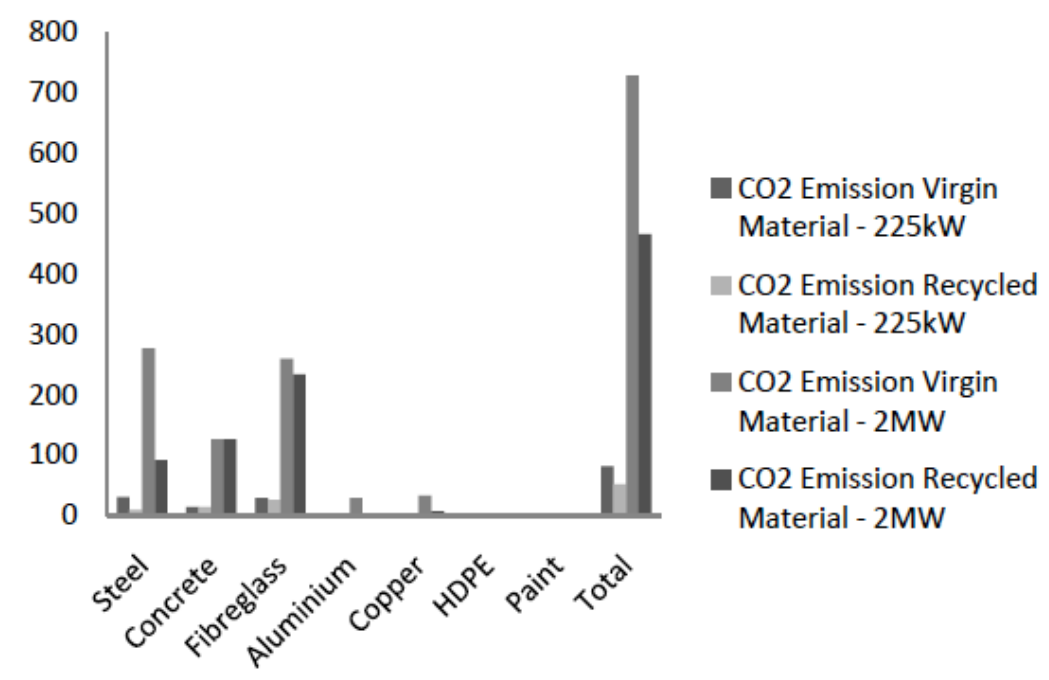

Figure 9: Comparison of Amount of Carbon Dioxide Emission from Various Materials [34].

It is noted that the amount of $\mathrm{CO}_{2}$ emissions in either case is higher when constructing wind technology with virgin rather than recycled material [34]. Hence, it is vital to consider, after the lifespan of the wind turbine is over (normally 20-25 years), dismantling and scraping the device for material reuse. As in most wind turbines, rotor blades are made of fibre glass reinforced by polyester, the tower is fabricated with steel while the base is made of steel reinforced armed concrete; hence recycling of such materials helps not only to reduce energy consumption and thus reduce carbon emissions, but also it is an economical payback for the initial money outlay. The percentage of recovery of material used in WT is shown in Figure 10.

Between the initial manufacturing and the recycling at the end of the life of the wind turbine, it is important that regular maintenance is undertaken to ensure the system remains operational for the maximum time.
Every device, including wind conversion technologies, entails a certain level of maintenance which in turn demands transportation of personnel for regular visits to complete oil changes, addition of lubricants, or the occasional cable change and cleaning (wiping up oil spill or leakage found in machinery). The amount of gas discharge is directly related with the amount of fuel used for transportation. As well as regular maintenance, there is often some WT that undertake dismantling or relocation to another site or upgrade and renovation. For the latter case, due to the fact that heavy trucks and cranes are the main tools for transportation, it is recommended that the distance of this process should not exceed $500 \mathrm{~km}$ [34]. Upgrading is normally implemented on turbines that have served almost half of their lifetime (12 to 15 years) in order to extend their lifetime for the full duration. Also, as technology is evolving and more efficient electronic devices are introduced to the market, it is sometimes

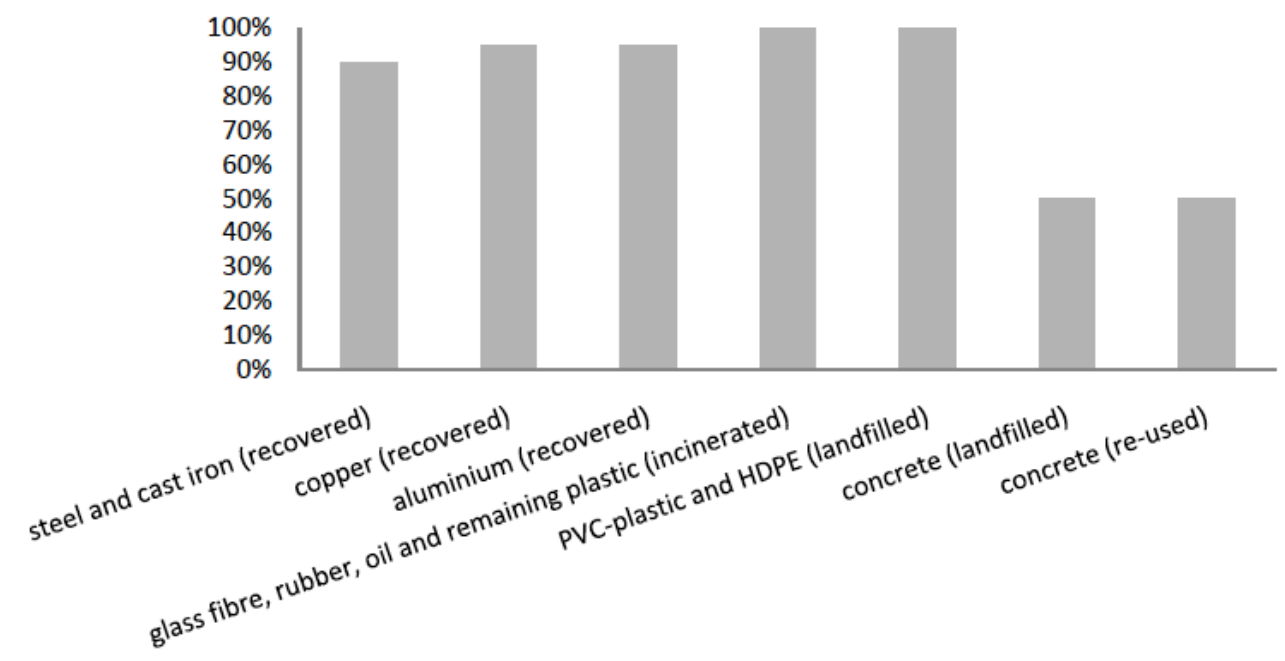

Figure 10: Percentage of Waste of Material Utilized in the Full Process of Wind Turbines [34]. 


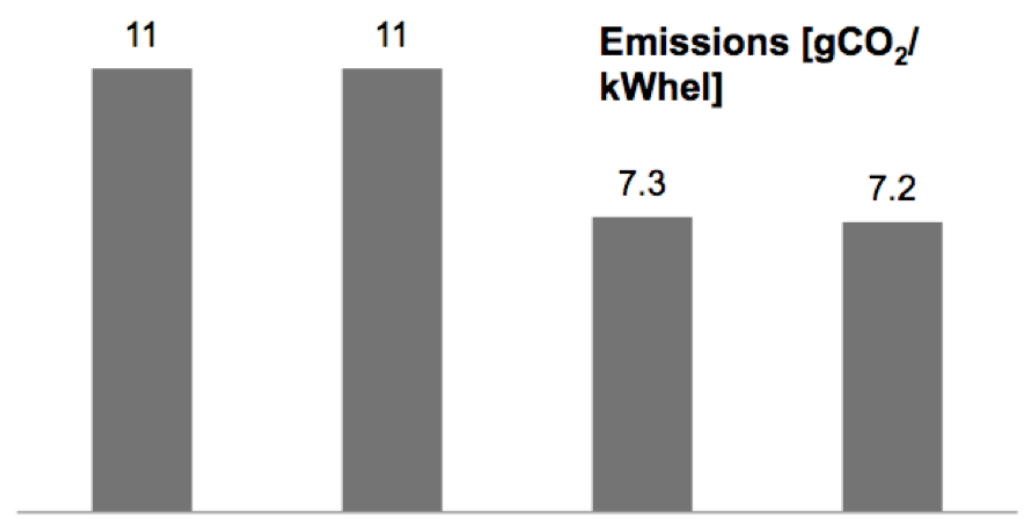

\section{Relocation Recycling Replacing New WT Renovation}

Figure 11: Emissions of $\mathrm{CO}_{2}$ for Various Alternatives of Wind Turbines.

an economical benefit to upgrade the turbine with the new technology especially during the maintenance period to prevent any unplanned interruption as well as to reduce the transportation footprint and also possibly increase efficiency.

With all the above mentioned possibilities and requirements in embracing renewable energy sources as a carbon neutral device, relocation, renovation, replacing and recycling of materials are hence major contributors to emissions when discussing wind turbines. Based on a study by Martinez, the component whose recycling most favors the recuperation of environmental resources is the tower, with $52 \%$ of the total general value recovered by all the processes of recycling [31]. Secondly, the nacelle (31\%) which is then followed by the rotor (10\%) and foundation (7\%).

Figure 11 represents the impacts of these factors on the $\mathrm{CO}_{2}$ emissions. It graphically symbolizes the four options showing recycling and relocation have similar higher emission rates while renovation is the lowest in gas release but the most expensive approach. However, more factors must be considered when analyzing the various components that pollute the environment. The installation location (offshore or inland) has a huge impact on the amount of greenhouse emissions. It is evident that greenhouse emissions are superior in offshore installations since requirements of concrete, steel and energy consumption for the foundation are much larger than in land for the same power capacity turbines, in addition to the fact that the base lifetime is almost half that expected with an onshore installations [35].

This outline of the indirect emission shows the integral feature that needs to be considered when defining a wind turbines carbon footprint and how direct emissions cannot be the only important factor considered.

\section{COST OF EMISSIONS AVOIDED}

Although the direct and indirect emissions are important to understand, when trying to quantify the amount of greenhouse gas emissions, it is noted that such emissions are negligible. It is best to compare the amount of $\mathrm{CO}_{2}$ combined cycle gas turbine (CCGT) against open cycle gas turbines (OCGT) which due to the intermittency of wind is required for backup since other solutions such as energy storage are uneconomical. The cost of emissions avoided by wind power has been calculated by Lang who defines it as "the cost of substituting wind power plus OCGT backup for CCGT" [36]. Table 1 outlines a cost comparison of emissions avoided when considering wind and a backup opposed to CCGT.

The values in Table 1 were calculated based on the assumption that the cost of wind backup generation is $50 \%$ of the cost of generating with OCGT ( $\$ 78 / \mathrm{MWh})$ at $30 \%$ capacity factor and the greenhouse gas emission

Table 1: Cost of Emissions Avoided

\begin{tabular}{|c|c|}
\hline Cost per MWh to substitute Wind with backup for CCGT (\$/MWh) & 67 \\
\hline Emissions avoided $\left(\mathrm{t} \mathrm{CO}_{2}\right.$-e/MWh) & 0.058 \\
\hline Cost of emissions avoided $\left(\$ \mathrm{CO}_{2}-\mathrm{e}\right.$ avoided $)$ & 1,149 \\
\hline
\end{tabular}


Table 2: Technology Comparison for Reducing Emissions [36]

\begin{tabular}{|c|c|c|c|}
\hline & $\begin{array}{c}\text { Emissions } \\
\left.\text { (t CO}{ }_{2}-\mathrm{e} / \mathrm{MWh}\right)\end{array}$ & $\begin{array}{l}\text { Emissions Avoided } \\
\text { (t } \mathrm{CO}_{2}-\mathrm{e} / \mathrm{MWh} \text { Avoided) }\end{array}$ & $\begin{array}{c}\text { Cost of Emissions } \\
\text { Avoided } \\
\text { (\$t CO } \mathrm{CO}_{2} \text {-e Avoided) }\end{array}$ \\
\hline $\begin{array}{l}\text { Wind (including backup generation) in } \\
\text { Australia }\end{array}$ & 0.519 & 0.058 & 1,149 \\
\hline $\begin{array}{l}\text { Clean coal (integrated gasification (IGCC) + } \\
\text { carbon capture and storage (CCS)) }\end{array}$ & 0.176 & 0.765 & 56 \\
\hline $\mathrm{CCGT}+\mathrm{CCS}$ & 0.108 & 0.833 & 47 \\
\hline CCGT & 0.577 & 0.364 & 33 \\
\hline Nuclear & 0.060 & 0.88 & 22 \\
\hline
\end{tabular}

factors for gas turbines $0.751 \mathrm{t} \mathrm{CO}_{2}-\mathrm{e} / \mathrm{MWh}$ and $0.577 \mathrm{t}$ $\mathrm{CO}_{2}$-e/MWh for OCGT and CCGT, respectively [36]. This table shows that wind power is a costly way to reduce $\mathrm{CO}_{2}$ especially as the amount of emissions avoided is very small. The projected cost of electricity, amount of emissions avoided and avoidance cost per $\mathrm{MWH}$ for future base load electricity generation technologies is depicted in Table 2.

Table 2 shows that wind power has the highest cost for avoiding emissions but has the tendency to save on emissions if emissions from backup are taken into account. Otherwise, if cost of backup is ignored, wind energy is found to be a suitable green source.

\section{CONCLUSION}

After discussing where the hidden emissions of carbon dioxide takes place in the full life span of wind energy technologies, is it still possible to say that these devices are carbon free? This paper presents the protocols of both direct and indirect carbon dioxide emissions and their presence when applying wind energy systems for power generation. It is clear from the above discussion that wind turbines generate $\mathrm{CO}_{2}$ and they are only zero direct carbon emission devices. However, with all these indirect emissions generated during manufacturing, installation, maintenance and removal, wind energy conversion systems are still the least contributors to climate change when compared to traditional energy sources. Hence, in order to mitigate the amount of $\mathrm{CO}_{2}$ in the air, such technology is regarded as an acceptable solution. According to the Kyoto protocol, power generation constitutes one of the largest industries in the production of greenhouse gases; hence in order to reduce emissions, renewable sources and in particular wind is the key for a greener future.

\section{REFERENCES}

[1] European Wind Energy Association, Wind energy and the environment: environmental benefits, external costs, local impacts, public acceptance, http://www.enerverde.eu/cms/ download/factsheet_environment2.pdf, accessed 10/05/2011

[2] Sahin AD. Progress and recent trends in energy. Progr Energy Combust Sci 2004; 30(5): 501-43. http://dx.doi.org/10.1016/j.pecs.2004.04.001

[3] White D. Reduction in carbon dioxide emissions: estimating the potential contribution from wind-power. Renewable Energy Found 2004.

[4] Joselin Herbert GM, Iniyan S, Sreevalsan E, Rajapandian S. A review of wind energy technologies. Renewable Sustainable Energy Rev 2007; 11(6): 1117-45. http://dx.doi.org/10.1016/j.rser.2005.08.004

[5] Manwell JF, McGowan JG, Rogers AL. Wind energy explained, Wiley, Chichester, UK 2002. http://dx.doi.org/10.1002/0470846127

[6] Riegler H. HAWT versus VAWT: small VAWTs find a clear niche. Refocus 2003; 4(4): 44-46. http://dx.doi.org/10.1016/S1471-0846(03)00433-5

[7] Sahin AD. Progress and recent trends in wind energy. Progr Energy Combust Sci 2004; 30(5): 501-43. http://dx.doi.org/10.1016/j.pecs.2004.04.001

[8] Thomas BG, Urquhart J. Wind energy for the 1990's and beyond. J Energy Conver Manag 1996; 37(12): 1741.

[9] Ackerman T, Soder L. Wind energy technology and current status: a review. Renewable Sustainable Energy Rev 2000; 4(4): 315-74.

http://dx.doi.org/10.1016/S1364-0321(00)00004-6

[10] Robert WT, Darrell MD. Trends in the evolution of wind turbine generator configurations and systems. Wind Energy 1998; 1(1): 70-85.

[11] Shankar PN. Development of vertical axis wind turbines, Proc Ind Natl Sci Acad 1980; 2(1): 49-66.

[12] Brothers C. Vertical axis wind turbines for cold climate applications, Renewable Energy Technologies in Cold Climate, Private Communication, Montreal 1998.

[13] Paraschivoiu I. Wind turbine design with emphasis on darrieus concept, Polytechnic International Press, Montréal, Canada 2002.

[14] Seki K, Simizu Y, Matsumoto T. A study of straight blade VAWT and its application, Proceeding of European Wind Energy Conference, Hamburg, Germany 1984; pp. 436-442.

[15] American Wind Energy Association, The most frequently asked questions about wind energy, www.awea.org, accessed 10/05/2011.

[16] Bureau of Land Management, Wind energy development programmatic environmental impact statement, 
http://windeis.anl.gov/documents/docs/WindFAQ21Jun05.pdf , accessed 10/05/2011.

[17] European Wind Energy Association, Wind energy and the environment: environmental benefits, external costs, local impacts, public acceptance, http://www.enerverde.eu/cms/ download/factsheet_environment2.pdf, accessed 10/05/2011.

[18] Herzog T. World greenhouse emissions in 2005, World Resources Institution, Washington, USA 2009.

[19] ETAP, The Carbon Trust helps UK businesses reduce their environmental impact, 2007, http://ec.europa.eu/ environment/_etap/pdfs/jan07_carbon_trust_initiative.pdf, accessed 10/05/2011.

[20] Parliamentary Office of Science and Technology, Carbon footprint of electricity generation. Postnote 2006; 268: 1-4.

[21] Wiedmann T, Minx J. A definition of 'carbon footprint', Nova Science Publishers, Hauppauge, USA 2008.

[22] Carbon footprint, What is carbon footprint, http://www.carbonfootprint.com/carbonfootprint.html, accessed 10/05/2011.

[23] Huang YA, Weber CL, Matthews HS. Categorization of scope 3 emissions for streamlined enterprise carbon footprinting. Environ Sci Technol Policy Anal 2009; 43(22): 8509-15.

[24] Matthews HS, Hendrickson CT, Webber CL. The importance of carbon footprint estimation boundaries. Environ Sci Technol Viewpoint 2008; 42(16): 5839-42.

[25] Santillan J, Heaston MS, Woodward DS, Joshi MM. Environmental impacts associated with manufacturing of solar and wind power alternative energy systems. Remediation 2010; 20(2): 107-13. http://dx.doi.org/10.1002/rem.20243

[26] Fleck B, Huot M. Comparative life-cycle assessment of a small wind turbine for a residential off grid. Renewable Energy 2009; 34(12): 2688-96.

http://dx.doi.org/10.1016/j.renene.2009.06.016

[27] Davidsson S. Life cycle exergy analysis of wind energy systems: assessing and improving life cycle analysis methodology, UPPSALA Universitet, Master's Thesis, July 2011, http://uu.diva-portal.org/smash/get/diva2:435510/ FULLTEXT01, accessed 30/08/2013.
[28] Crawford $\mathrm{RH}$. Life cycle and greenhouse emissions analysis of wind turbines and the effect of size on energy yield. Renewable Sustainable Energy Rev 2009; 13(9): 2653-60. http://dx.doi.org/10.1016/i.rser.2009.07.008

[29] Lee YM, Tzeng YE, Su CL. Life cycle assessment of wind power utilization in Taiwan, Proceeding of the 7th International Conference on Eco Balance, Tsukuba, Japan Nov 14-16, 2006

[30] Ardente F, Beccali M, Cellura M, Brano VL. Energy performances and life cycle assessment of an Italian wind farm. Renewable Sustainable Energy Rev 2008; 12(1): 20017. http://dx.doi.org/10.1016/j.rser.2006.05.013

[31] Martinez E, Sanz F, Pellegrini S, Jiménez E, Blanco J. Life cycle assessment of multi-megawatt wind turbine. Renewable Energy 2009; 34(3): 667-73. http://dx.doi.org/10.1016/j.renene.2008.05.020

[32] Ekvall T, Wedema BP. System boundaries and input data in consequential life cycle inventory analysis. Int $\mathrm{J}$ Life Cycle Assessm 2004; 9(3): 161-71. http://dx.doi.org/10.1007/BF02994190

[33] Nalikowe BB, Liu J, Damien W, Lukawski T. Life cycle assessment of a wind turbine, http://www.infra.kth.se/fms/ utbildning/lca/projects\%202006/Group\%2007\%20 (Wind\%20turbine).pdf, accessed 10/05/2011.

[34] Rydh CJ, Johnson M, Lindhal P. Replacement of old wind turbines assessed from energy, environmental and economic perspectives, European Union Project: Wind Energy in the Baltic Sea Region Final Report 2004.

[35] Jungbluth N, Bauer C, Dones R, Fischknecht R. Life cycle assessment for emerging technologies: case studies for photovoltaic and wind power. Int J Life Cycle Assessm 2005; 10(1): 24-34

http://dx.doi.org/10.1065/lca2004.11.181.3

[36] Lang P. Cost and quantity of greenhouse gas emissions avoided by wind generation, Industrial Wind Action Group, Feb 2009, http://carbon-sense.com/wp-content/uploads/ 2009/02/wind-power.pdf, accessed 30/08/2013. 